\title{
29 Human and social issues in the age of informatics
}

\author{
Ronald E. Anderson \\ University of Minnesota \\ Minneapolis, USA
}

\begin{abstract}
Information technology has opened up many new issues that must be confronted by societies, communities, schools, teachers and students. An international survey in 1992 of students in 12 countries found evidence of widespread student disregard of ethical standards related to two of these human-technology issues. Specifically, a large share of the students in many countries supported unauthorised software copying and computer-aided privacy violation. Various strategies are needed for addressing such human and social issues in the classroom.
\end{abstract}

\section{Keywords}

Information technology, implications, philosophy, attitudes, evaluation, teaching methods.

\section{INTRODUCTION}

The question addressed is what are the human and social issues raised by the introduction of computer technology in schools, with special attention given to the case of mathematics, and what relevant actions might be taken by educators to deal with the challenge. Before considering the educational relevance of human issues of information technology, it may be helpful to review what are generally considered to be the issues. Below are a list of themes and illustrative questions representing the key issues that have been discussed in the literature over the past three decades. This list of themes relies extensively upon a discussion by Rob Kling (1966). The list begins with broader societal or institutional issues and narrows down to those more of concern to individual lifestyles. 
238 Information and communications technologies in school mathematics

The issues

Democratisation: Does information technology (IT) result in threats to democracy because of large information systems that lend themselves to centralised control? To what extent does IT provide new opportunities to access government information and otherwise strengthen democratic processes?

Productivity and the economy: Does IT really contribute to the economy across the board? Does the productivity gain of new information technologies justify their cost?

Employment: How does computerisation impact different occupations? Is it creating an economy with fewer jobs overall?

Quality of the workplace: Does computerisation tend to degrade or upgrade or enhance the workplace? Can IT improve the flexibility of work schedules and locations?

Societal class divisions: Does IT increase wealth differentiation and does it more sharply divide the haves and have nots? Does it foster an underclass and/or a tier of low level jobs from which it is difficult to move? Does a lack of either technological literacy or information literacy magnify social divisions?

Quality of information: To what extent does the availability of technical publications via the Web contribute to or detract from high-quality scholarship and the advancement of knowledge? How should students be taught to evaluate information in such environments?

Human risk: How safe are information systems, particularly those which control risk, e.g., air traffic control and radiation treatment systems? Should designers of such systems be licensed? How can human safety be preserved when large software systems cannot be proven to be free of bugs? How much do computerised weapons increase the risk of nuclear war and other major disasters? Does the public underestimate the safety of electronic warfare?

Health: What is the magnitude of health risk posed by particular computerised systems to different social groups? To what extent are end-users threatened by low-level radiation, noise, repetitive strain injuries, and eyestrain? What aspects of equipment or workplaces need to be regulated?

Technological literacy: What kinds of knowledge and skills are needed by all students in societies with large-scale computerised information systems? How can educational systems keep up with the delivery of these skills when the technology changes so rapidly?

Education: Can and does IT significantly improve instructional opportunities by either facilitating the construction of interesting, structured tutorials; or opening up more and better unstructured learning activities like simulations and Internetbased searches and retrievals? Are there other benefits or drawbacks from 
bringing computers into the schools? Overall, to what extent does 'edutainment' facilitate or detract from learning?

Equity in education: In many countries a major share of education in using IT occurs in the home. Can disparity in informatics skills across socio-economic groups be contained? Are inequities for disadvantaged racial or ethic groups such as immigrants resolvable? Why do women tend to leave school technology tracks (advanced degree programs in informatics) the further they get into them? Even though there have been many gender equity programs in schools, why do women predominate in data entry jobs or profession roles like librarians, whereas men prevail in jobs that specify requirements or otherwise control information systems? In educational systems where informatics is optional, students enter mathematics courses with very unequal knowledge and skill in computing. To what extent does the lack of IT experience create unfair disadvantage in learning, particularly when computer-based exercises are assigned? What base of IT knowledge and skill should students be expected to have for different levels of mathematics instruction?

Freedom: To what extent should individuals have freedom of expression on-line? When is it necessary to censor materials transmitted by individuals over local or global networks? To what extent should owners of computer systems have legal protection from curious programmers that enjoy entering new systems and 'looking around' with or without damage to software and with or without theft of information? Should certain groups like terrorists and convicted criminals be allowed to communicate electronically without police monitoring?

Intellectual property: To what extent should property laws be extended to intellectual products in electronic form? To what extent should students be encouraged to place information products like software in the public domain or as shareware rather than release them as copyrighted or patented products at a fee? How serious is it to overlook different types of violations of software copyrights, ranging from making a copy for a friend to pirating software?

Privacy: To what extent should a citizen's (or an employee's) e-mail and personal files be protected from access or monitoring by others? Are there good technological solutions like encryption that help to protect the privacy of personal information? Should electronic monitoring of convicted offenders, e.g., home detention, be encouraged?

Of course, these are not all of the relevant human or social issues produced by information technologies. However, these themes and their exemplary questions represent a set of major issues that appear to be enduring and important questions to address. Next some data are presented from a large international study that illuminate how students in many countries are thinking about the last two issues above, intellectual property and privacy. 


\section{STUDENT ATTITUDES ON PRIVACY AND PROPERTY}

In 1992 the International Association for the Evaluation of Educational Achievement (IEA) Computers in Education Study surveyed schools in twelve countries, but only ten included questions on ethics: Austria, Bulgaria, Germany, Greece, India, Japan, Latvia, Netherlands, Slovenia, and the United States. Each country surveyed a scientifically selected, representative sample of schools and students within schools. Within each school, surveys were completed by a principal, computer co-ordinator, and a randomly selected classroom of students along with its teacher. All survey questionnaires were translated into the national language of each country, then another translator back-translated the survey questions into the English language so that the consistency of the translation could be double checked. Over 69,000 students in grades 5,8, and 11 (ages 10, 13 and 16) in 2,500 schools were tested during 1992 (Pelgrum, Reinen and Plomp, 1993). Students were given two ethical scenarios and were asked to agree or disagree with an aspect of the scenario. The first scenario deals with the intellectual property issue of illegal software copying.

Scenario 1: John buys a new computer game that runs on his family's computer as well as those at his school. Even though the diskette was 'copy protected' and the label warned not to try to copy it, he discovered that he could copy it using a special copy program. John liked the game program and made copies for each of three of his friends. One of John's teachers overheard them talking about these copies and told them it was wrong to make such unauthorised copies. John replied that "We always make copies. If my friends buy a game, they give me a copy, and I'm expected to do the same for them. Besides, no one has ever checked up on us." The student was asked "Do you agree or disagree with John?"

The second scenario addresses issues of privacy and confidentiality.

Scenario 2: Nancy notices that her history instructor also buys books from the same store. Upon Nancy's request, the store clerk gives Nancy a computer listing of all the books her teacher had bought. When the history instructor finds out, she gets very angry and storms to the bookstore saying, "You should not give the names of the books I buy to anybody. Nobody has the right to know what books I am reading." The student was asked "Do you agree or disagree with Nancy's teacher?"

In each case the students were given the response categories: 'strongly disagree,' 'slightly disagree,' 'slightly agree,' and 'strongly agree.' It is possible to infer from the student responses to these scenarios the degree to which they tolerate illegal software copying and the extent to which they support a claim to personal data privacy. It is important to keep in mind that most codes of ethical computing define the behaviour in each of these scenarios as unethical. 
Within country by grade subgroups, between $15 \%$ and $67 \%$ of the students expressed tolerance of unauthorised software copying and $22 \%$ to $64 \%$ expressed tolerance of computer-aided privacy violation. On the average across all countries about $35 \%$ of the students tolerated the privacy invasion and about $50 \%$ of the students tolerated the illegal copying of software. The mere magnitude, as well as the range, of tolerance for these behaviours is of concern.

- Only three of the nations involved in the IEA study (Austria, Japan, and the USA) surveyed students at both the 8th and the 11th grade levels. In all three countries the 11th grade students gave more tolerant responses to software copy violation than the 8th grade students. But the 11th grade students were less tolerant of privacy violation than the 8th grade students.

- Variations across countries were not as large as might be expected. One exception was India where a large majority of students expressed tolerance of privacy violations. Another comparative finding tends to contradict national stereotypes. Specifically, students in Japan tended to be less likely, not more likely, than in the USA and Western Europe to tolerate illegal software copying. In 1992 Japan had not yet introduced their new informatics curriculum, so the exposure of students to IT was behind that of the USA and Western European countries. Perhaps this yielded less pressure upon Japanese students to violate software copying norms.

- Students in the United States were analysed separately to determine whether or not greater knowledge of, and experience with, computers resulted in more ethically oriented opinions. It was found that the more American students took computer-related coursework, the more likely they were to tolerate computer-aided privacy violation. This occurred despite the fact the higher the students' computer literacy, the less tolerant they were of such violation. So, it appears that the negative effect may be due not to students' knowledge and skill, but to classroom learning.

- This pattern did not appear with tolerance of software violations, however. In all cases the acceptance of illegal software copying was greater in the 11th grade compared to the 8th grade. Two contradictory forces appear to be operating. One is the traditional curriculum in which the typical introductory informatics course gives students greater awareness of the ethical implications of software copying. The other major socialisation force might be called the 'hidden curriculum' where students increasingly feel pressure from peers to engage in illegal software copying, coupled with a greater appreciation of the personal benefits of doing so.

- The IEA data show that a large share of contemporary youth tend to support unethical conduct involving computer technology, that involves violation of personal privacy and software copyright. Privacy and intellectual property are two of the most important ethical and social issues facing science and technology today. These two issues are significant not only because they are controversial and have economic impact, but because a gap exists between ethically-relevant social norms and common practice. 
- The Guidelines of the ACM Code of Ethics specifies an obligation to protect personal data about individuals "from unauthorised access or accidental disclosure to inappropriate individuals" (Anderson, 1992; Anderson, Johnson, Gotterbarn, and Perrolle, 1993; Anderson, 1994). The ACM Code also states that organisational leaders have obligations to verify that systems are designed and implemented to protect personal privacy. In this scenario the bookstore should have had policies and procedures that protected the identity of its customers. Accordingly, neither the store clerk nor Nancy should have accessed the personal data on the teacher. Nonetheless, unauthorised access and use of private data occurs in the United States with some degree of frequency. However, in a number of other countries such access is legal and not be considered unethical by their citizens.

- National and local laws, as well as the cultural norms, with respect to information vary greatly across national systems. This is particularly true for privacy and intellectual property. While cultural differences abound, the global information economy increasingly depends upon respect for intellectual property and common norms for information privacy across all nations participating. In most industrialised countries there are laws prohibiting violations of software licenses and copyright ownership. All major associations of IT professionals define these violations as unethical (Anderson 1992, 1994). In this context, the IEA attitude data provide the basis for serious concern about what, how, and where our students are learning their conceptions of appropriate decision making about social issues pertaining to IT.

\section{INSTRUCTIONAL STRATEGIES}

How should the mathematics teacher address these many, complex issues? Consider some alternative strategies for addressing these issues in the classroom.

Taking responsibility: It may seem irrelevant to the mathematics teacher to address social issues, but if they are not addressed in the classroom, how will students learn about them? If the school does not have an informatics teacher that addresses these issues, then the technology-using mathematics teacher has a special obligation to help students understand the issues and how they are relevant to using IT at school and home. Not all the issues have to be discussed with students, but it is imperative that at least some issues such as privacy and intellectual property are addressed. Otherwise, not only are the students not prepared for the technology world outside of school, but they might also put their own school computers or networks at great risk by damaging files, fraudulent manipulation of school records, and so forth. 
Rules and norms: Students have been known to conduct a widening variety of costly damage to information systems including

- cracking (breaking) into systems without authorisation;

- copying commercial, copyrighted software;

- crashing (shutting down) computer systems without authorisation;

- tampering with data, e.g., grades;

- using another's algorithm without acknowledgement of source (or modifying without 'informing').

While some educators have lauded such actions because they result in useful information regarding system vulnerability, damages from these actions have resulted in huge financial loss. Such actions clearly violate principles within most professional standards of fair or ethical IT-related conduct. Students need to know the ethical and legal implications of such actions. It is most appropriate, and potentially effective, for a school system to abstract it's own rules and standards regarding actions with technology. These policies should be clearly posted and can serve as a basis for classroom discussions about appropriate and inappropriate behaviour. In the case of mathematics and computer science this becomes particularly important in terms of students' experience and expertise relative to the bullet points above.

Preparing teachers: When an instructor chooses to have students work with computer technology, they have an obligation to ensure that their students are informed about the legal and ethical boundaries around acceptance of technologyrelated actions. This means the teachers have to first be educated in these issues and appropriate actions. Suppose a teacher becomes aware of students participating in potentially illegal or unethical conduct, what should the teacher's response be and how should the school train the teacher to deal with these situations? This is not an easy situation to deal with and one that is too often neglected.

Curriculum: One strategy is to have a course or course unit within the informatics curriculum addressing social and ethical issues. But some argue that it is more effective to infuse content on these issues into any or all courses using information technology. While the debate continues, the ImpactCS project has developed frameworks for teaching social and ethical issues within either curricular approach. Information about the reports and products of this project can be obtained from the Internet ${ }^{1}$.

Artz (1996) recently proposed another useful paradigm for analysing and teaching human and social issues. He describes how an instructor can use a 'Quality of Life' principle to help students learn how to make ethical IT decisions. Thanks to computer 'viruses,' network crashes, and other emerging costly technological risks, awareness of the need for personal (and ethical) responsibility in the context of information technology has grown rapidly. Never-the-less, normative standards and ethical codes of conduct on such issues as intellectual property and 
244 Information and communications technologies in school mathematics

personal privacy continue to be ignored and violations are rampant across the globe.

\section{SUMMARY}

Information technology has opened up many issues that must be confronted by societies, communities, schools, teachers and students. The IEA Computers in Education surveys found evidence of widespread student disregard of two of these general human or social (and ethical) issues. Specifically, a large share of the students in many countries accepted unauthorised software copying and computeraided privacy violation.

Effort should continue to be invested to improve understanding of the issues, where students and teachers stand on them, and how they might most effectively be addressed in the curriculum and in the classroom, with particular attention given to school mathematics and computer science courses. Existing approaches and materials for teaching about these issues should be collected, reviewed and evaluated. The challenge will be to develop agendas for research, curriculum development, as well as teaching.

\section{REFERENCES}

Anderson, R. E., (1992) Social Impacts of Computing: Codes of Professional Ethics, Social Science Computer Review. 10(4).

Anderson, R. E., Johnson, D. G., Gotterbarn, D., and Perrolle, J. (1993) Using the new ACM Code of Ethics in Decision Making, Communications of the ACM 36(2) 98-107.

Anderson, R. E., (1994) The ACM Code of Ethics: History, Process, and Implications, in Huff, C. and Finholt, T. (eds) Social Issues in Computing, NY: McGraw-Hill.

Artz, J. (1996) A Quality of Life Perspective, Computers and Society, 26(3) 712.

Kling, R. (ed.) (1966) Computerization and Controversy, 2nd Edition, Academic Press.

Pelgrum, W. J., Janssen Reinen, I. A. M. and Plomp, T. (1993) Schools, Teachers, Students and Computers: A Cross-National Perspective. Center for Applied Educational Research, University of Twente, Encshede, The Netherlands.

Note: Internet Web Site Reference

1 http://www.seas.gwu.edu/seas/impactes/index.html 


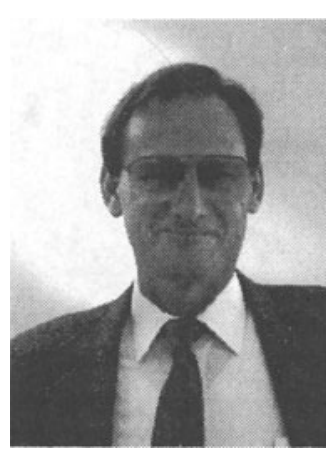

Ronald E Anderson is Professor of Sociology at the University of Minnesota. He has written several books and over fifty articles on computing applications. He serves as Co-editor for Technology-based Education for Kluwer Academic Publishing. Between 1990 and 19976 he has served as Director of the United States part of the IEA international study of computers in education. Currently he is conducting a large-scale survey of teachers, investigating their participation in constructivist activities and use of instructional technologies. 